
\title{
Reseserch Suare \\ The Influence of LightPath Length on the Color of Flame-Fusion Synthetic Ruby
}

\section{Bin Yuan}

China University of Geosciences (Beijing)

Ying Guo ( $\sim$ guoying@cugb.edu.cn )

China University of Geosciences (Beijing)

\section{Ziyuan Liu}

China University of Geosciences (Beijing)

\section{Research Article}

Keywords: UV-Vis, light spectrum, standard light, color difference

Posted Date: December 9th, 2021

DOI: https://doi.org/10.21203/rs.3.rs-1134748/v1

License: (c) (1) This work is licensed under a Creative Commons Attribution 4.0 International License. Read Full License 


\title{
The Influence of LightPath Length on the Color of flame-fusion
}

\section{synthetic ruby}

\author{
Bin Yuan ${ }^{1}$, Ying Guo ${ }^{2, \star}$ \& Ziyuan Liu ${ }^{3}$ \\ 1 Department of Gemmology, China University of Geosciences (Beijing), 100083, China. \\ E-mail:2296205854@qq.com \\ 2 Department of Gemmology, China University of Geosciences (Beijing), 100083, China. \\ E-mail:guoying@cugb.edu.cn \\ 3 Department of Gemmology, China University of Geosciences (Beijing), 100083, China. \\ E-mail:1059800843@qq.com \\ * Corresponding Author
}

Abstract

Colorimetric studies of different light path lengths from a new perspective of UV-Vis spectroscopy. The corrected ultraviolet-visible light spectrum was used to calculate the color of flame-fusion synthetic ruby, and the influence of light path length and standard light source on the color of flame-fusion synthetic ruby was studied. The results show that the $L^{*}, C^{*}, h^{\circ}$ under the A light source are higher than those under the D65 light source. In the ultraviolet-visible light spectrum, the strong absorption band of $\mathrm{Cr}^{3+}$ at $545 \mathrm{~nm}$ is the main cause of the color of the ruby. As the length of the light path increases, the absorption peak area at $545 \mathrm{~nm}$ also increases, the lightness $L^{*}$ decreases, and the hue angle $h^{\circ}$ increases. The chroma $C^{*}$ first increases as the length of the light path increases, and then begins to decrease under the influence of the continuous decrease in lightness. The color difference $\Delta \mathrm{E}^{*}$ ab reaches the maximum when the light path length is around $10 \mathrm{~mm}$, and the standard light source has the greatest influence on the color difference $\Delta \mathrm{E}^{*}$ ab. As the length of the light path continues to increase, the influence of the standard light source on the color difference $\Delta \mathrm{E}^{*}$ ab decreases.

Introduction

Ruby is a kind of corundum with a beautiful bright red color. It is widely distributed all over the world, such as Myanmar, Thailand, Sri Lanka, Tanzania, etc. When Al in corundum is replaced by various elements such as $\mathrm{Cr}, \mathrm{Fe}, \mathrm{Ti}$, and $\mathrm{V}$, the corundum will show various colors. The color of ruby is related to $\mathrm{Cr}^{3+}$. And as the replacement of $\mathrm{Al}^{3+}$ by $\mathrm{Cr}^{3+}$ increases, the color will change from light pink to red $^{1,2}$. flame-fusion synthetic ruby is the most common type of synthetic ruby. Compared with natural ruby, it has a pure texture and is more suitable for chromaticity research.

There are many ways to evaluate the color of gems.The most common is the Cape series diamond color grading. The grader compares the diamond to be graded with a standard colorimetric stone to determine the color grade of the diamond $3,4,5$. However, in addition to diamonds, it is difficult to determine the color grade of other gemstones in this way, and because it is artificially graded, there may be large errors.The CIE standard colorimetric system can effectively solve this problem, of which the CIE1931-XYZ system and the CIE1976L*a*b uniform color space are the most widely used.Stockton ${ }^{6}$ first used the Gem ColorMaster instrument to quantify the color of peridot in the CIE1931 color space.But the CIE1931-XYZ system is a non-uniform color space and cannot describe the color of gems well.The CIE1976L ${ }^{*} a^{*} b$ uniform 
color space is modified based on the CIE1964 uniform color space, and it is widely used in gem color evaluation $7,8,9,10,11,12$.

The main instrument currently used to measure the color of gemstones is a spectrophotometer.The portable spectrophotometer is used to measure the color of perdiot ${ }^{13,14,15}$, amethyst ${ }^{16}$, turquoise ${ }^{17}$, rubellite ${ }^{18}$, and green chrysoprase ${ }^{19,20}$.Color i5 and GemDialogue color cards are used to quantitatively describe the color of jadeite ${ }^{21}$.In addition, computer vision systems can also be used to measure the color of jadeite ${ }^{22}$. Because the portable spectrophotometer is a closed system, it cannot effectively reflect the pleochroism of some gemstones.The use of ultraviolet-visible spectrophotometer can effectively solve this problem ${ }^{23}$.Compared with the portable spectrophotometer, the UV-Vis spectrophotometer measures color more objectively and accurately.The UV-Vis spectrophotometer calculates the colors of leaves ${ }^{24}$ and flowers ${ }^{25}$, garnets ${ }^{26,27}$, synthetic alexandrite ${ }^{28}$, dyed purple opal ${ }^{29}$, etc. by using CIE1931RGB and CIEXYZ color matching functions.

The human retina has three kinds of color photoreceptor cells, namely cone cells, that are sensitive to red, green, and blue light.S cones detect short wavelength (blue), $\mathrm{M}$ cones detects medium wavelength (green), L cones detect long-wavelength (red).When exposed to radiation,the spectral stimulus energy is absorbed by photoreceptors of the three cones.The cone cells produce different degrees of neurophysiological reactions.The International Commission on Illumination (CIE) has established a series of color matching functions through visual experiments. As a proxy for the cone response function, the CIE color-matching functions are used to express the linear combination of the average visual respons $\mathrm{e}^{30}$.The matching function can be used to calculate the energy of light that enters the human eye and produces the color perception.Sun ${ }^{28}$ discussed the influence of different path lengths on the color of synthetic $\mathrm{Cr}$-bearing chrysoberyl by calculating the color matching function.In addition, pleochroism is also a factor that needs to be considered when studying the color of gems ${ }^{31}$.

Two fully polished synthetic ruby cuboids $\mathrm{R}$ and Ru which have been oriented by an X-ray crystal orientation instrument are selected.Size is $5.89 \mathrm{~mm} \times 5.97 \mathrm{~mm} \times 9.29 \mathrm{~mm}$ and $5.46 \mathrm{~mm} \times$ $5.41 \mathrm{~mm} \times 8.9 \mathrm{~mm}$.The sample is shown in Figure 1 . The height is the c-axis, and the surface is perpendicular to the optical axis. The length and width of the gemstone are selected as the a-axis and $b$-axis.The $a, b$, and $c$ axes of the two samples are numbered respectively $R_{o a}, R_{o b}, R_{e c}, R u_{o a}$, $R u_{o b}, R u_{e c}$.This paper mainly uses the color matching function to quantitatively characterize the color, and studies the influence of the light path length and the light source on the color of the ruby. 


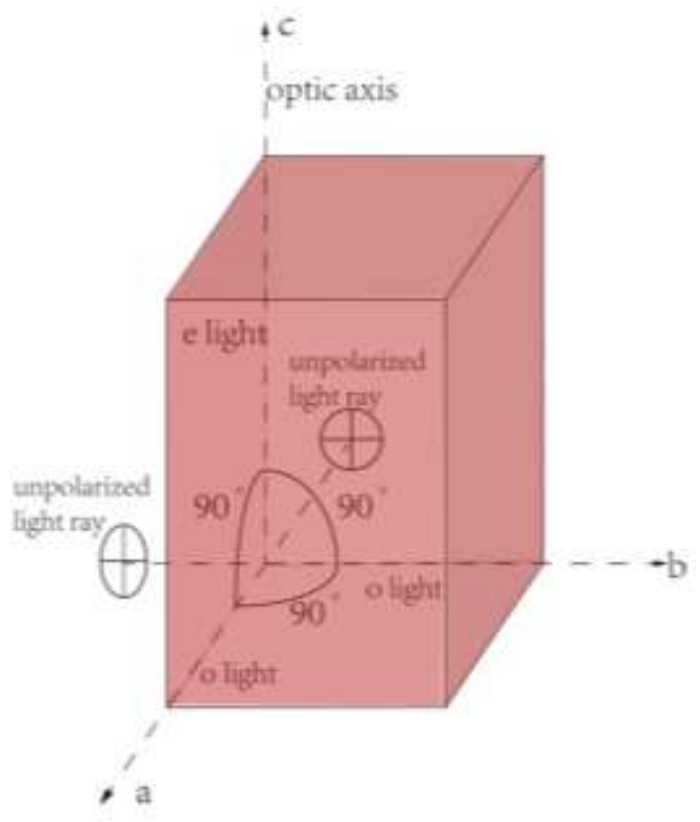

Figure 1.Schematic diagram of the sample. Three mutually perpendicular crystal axes $a, b$, and c. The unpolarized light parallel to the a-axis and the $b$-axis is split into o-light and e-light when passing through the crystal, and the unpolarized light parallel to the c-axis passes through the crystal along the optical axis

\section{Results and discussion}

\section{UV-Vis spectral analysis}

The UV-Vis spectrum of synthetic ruby is shown in Figure 2.It can be seen that there are obvious absorption peaks at $693.50 \mathrm{~nm}, 669 \mathrm{~nm}$, and $659 \mathrm{~nm}$, as well as broad absorption bands centered at $545 \mathrm{~nm}$ and $416 \mathrm{~nm}$.The absorption peak at $693.50 \mathrm{~nm}$ is the fluorescence emission peak caused by $\mathrm{Cr}^{3+}$, which is caused by ${ }^{2} \mathrm{E} \rightarrow{ }^{4} \mathrm{~A}_{2}$ of $\mathrm{Cr}^{3+}$, which is the reason for the strong fluorescence of synthetic ruby.The two weak absorption peaks at $669 \mathrm{~nm}$ and $659 \mathrm{~nm}$ are the ${ }^{4} \mathrm{~A}_{2} \rightarrow{ }^{2} T_{1}$ transition caused by $\mathrm{Cr}^{3+}$. The absorption peak near $581 \mathrm{~nm}$ is related to the charge transfer of $\mathrm{Fe}^{2+}-\mathrm{Ti}^{4+}$. The absorption peak at $528 \mathrm{~nm}$ is related to the ${ }^{2} \mathrm{D}$ splitting of the $\mathrm{Ti}^{3+}$ spectrum item ${ }^{32,33}$. The absorption peaks at $545 \mathrm{~nm}$ and $416 \mathrm{~nm}$ are the ${ }^{4} \mathrm{~A}_{2} \rightarrow{ }^{4} \mathrm{~T}_{2}$ transition caused by $\mathrm{Cr}^{3+}$, which absorb yellow-green light, allowing red light and a small amount of blue-violet light to pass through, forming the color of synthetic ruby. 


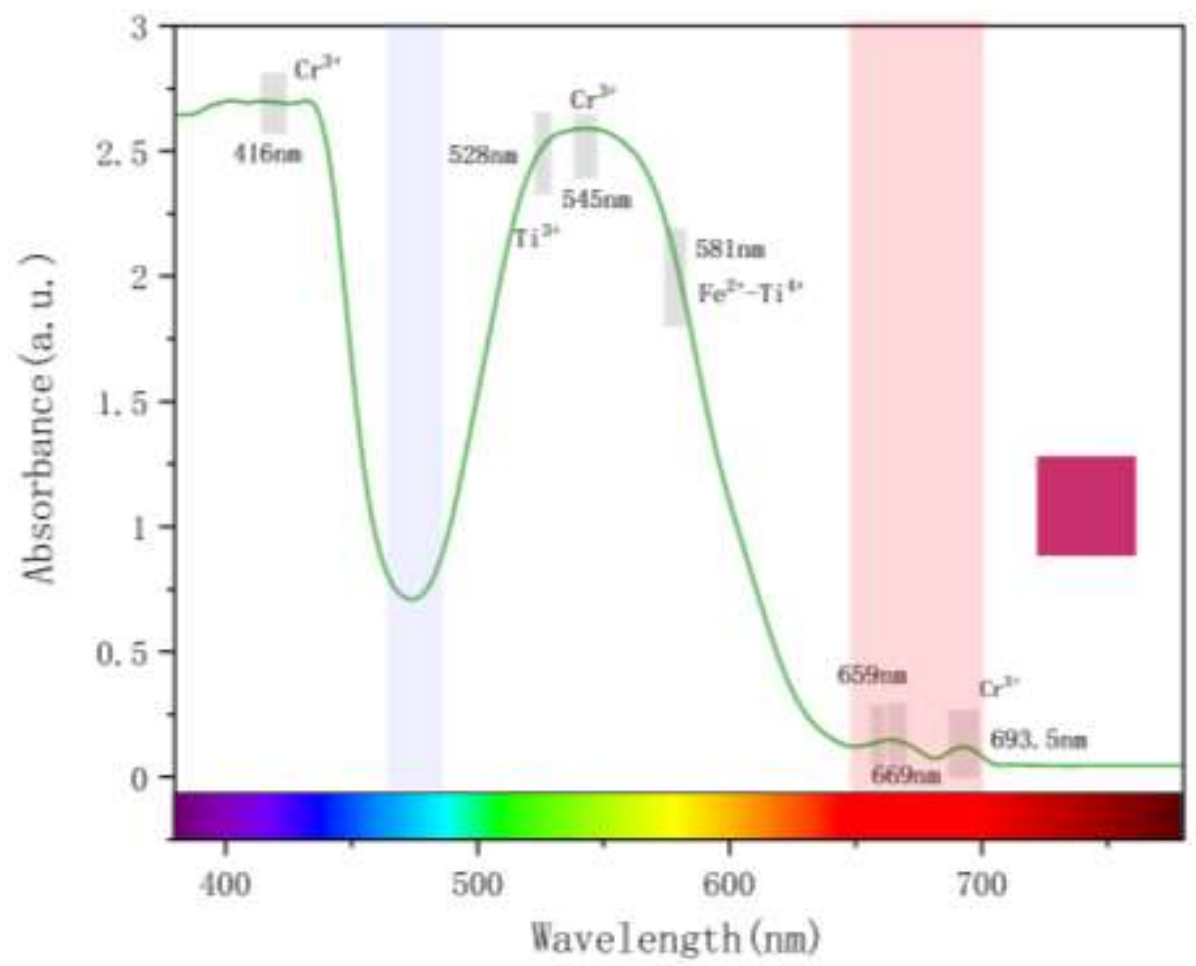

Figure 2. Ultraviolet-visible light spectrum of synthetic ruby $R_{o a}$.Two transmission windows appear at 652-700 and 465-480nm, which transmit red light and a small amount of blue-violet light

\section{Correcting the UV-Vis Spectra}

When light passes through the sample, energy is lost in three ways.A is the total absorbance of the sample measured directly from the spectrophotometer, including Ac (absorbance contribution of the absorber), Arl (absorption caused by light reflection at the boundary), Aisl (absorption caused by scattering of internal inclusions) ${ }^{26,28}$.

$$
\mathrm{A}=\mathrm{Ac}+\mathrm{Arl}+\mathrm{Aisl}
$$

There are many different methods to correct the baseline. For example, Sun ${ }^{26}$ subtracted the absorption spectrum at $800 \mathrm{~nm}$ to obtain a corrected spectrum.In this study, the Sellmeier equation is used to eliminate Arl and to correct the baseline of the ultraviolet-visible spectrum.At the same time because the sample is synthetic ruby with pure texture and no inclusions, Aisl does not affect the UV-Vis spectrum.Thus, the corrected UV-Vis spectrum is obtained.

The absorption (Arl) of light reflected at the boundary is related to the refractive index ( $n$ ) of the sample.The Sellmeier equation is an empirical formula that describes the refractive index and wavelength in a specific transparent medium and is used to determine the dispersion of light in the medium.Different materials have different Sellmeier coefficients. According to the research of Malitson ${ }^{32}$, we get the following Sellmeier formula:

$$
\mathrm{n}^{2}(\lambda)=1+\frac{\mathrm{B}_{1} \lambda^{2}}{\lambda^{2}-\mathrm{C}_{1}}+\frac{\mathrm{B}_{2} \lambda^{2}}{\lambda^{2}-\mathrm{C}_{2}}+\frac{\mathrm{B}_{2} \lambda^{2}}{\lambda^{2}-\mathrm{C}_{2}}
$$

Where $\mathrm{n}$ is the refractive index, $\lambda$ is the wavelength, and $B_{1,2,3}$ and $C_{1,2,3}$ are different Sellmeier coefficients.For corundum, there are the following Sellmeier equations in the direction of the corundum o light and the direction of the e light respectively:

$$
\mathrm{n}^{2}(\lambda)=1+\frac{1.4313493 \lambda^{2}}{\lambda^{2}-0.0726631^{2}}+\frac{0.65054713 \lambda^{2}}{\lambda^{2}-0.1193242^{2}}+\frac{5.3414021 \lambda^{2}}{\lambda^{2}-18.028251^{2}}
$$




$$
\mathrm{n}^{2}(\lambda)=1+\frac{1.5039759 \lambda^{2}}{\lambda^{2}-0.0740298^{2}}+\frac{0.55069141 \lambda^{2}}{\lambda^{2}-0.1216529^{2}}+\frac{6.5927379 \lambda^{2}}{\lambda^{2}-20.072248^{2}}
$$

It is assumed that in the ideal state when unpolarized light is incident perpendicularly to the surface of the gemstone, a certain length of optical path will not be generated inside.In this case, the light absorption inside the gem can be ignored. Therefore, the transmittance through the surface of the gemstone can be expressed as:

$$
\mathrm{T}=1-\mathrm{R}
$$

According to Lambert Beer's law, transmittance can be converted to absorbance:

$$
\mathrm{A}=\lg \frac{1}{\mathrm{~T}}=\mathrm{kbc}
$$

Where $\mathrm{A}$ is the absorbance, $\mathrm{T}$ is the transmittance, $\mathrm{k}$ is the molar absorbance coefficient, $\mathrm{c}$ is the concentration of the absorbing substance, and $\mathrm{b}$ is the optical path of the light.

$$
\begin{gathered}
\mathrm{T}=10^{-\mathrm{A}}=1-\mathrm{R} \\
\mathrm{A}=-\lg \mathrm{T}=-\lg (1-\mathrm{R}) \\
\mathrm{R}=\left(\frac{\mathrm{n}_{0}-\mathrm{n}_{1}}{\mathrm{n}_{0}+\mathrm{n}_{1}}\right)^{2} \\
A_{r l}=2 A=-2 \lg \left[1-\left(\frac{\mathrm{n}_{0}-\mathrm{n}_{1}}{\mathrm{n}_{0}+\mathrm{n}_{1}}\right)^{2}\right]
\end{gathered}
$$

$\mathrm{R}$ is the reflectivity, $\mathrm{n}_{0}=1$ is the refractive index of light in the air, $\mathrm{n} 1$ is the refractive index of light in the corundum, $T$ is the transmittance, and $A$ is the absorbance produced by single boundary reflection. Arl is the absorbance produced by the reflection of the two boundaries.

Accurate visible spectroscopic measurements rely on correct calibration of the spectral baseline.Figure 3 shows the spectrum of baseline correction performed by the Sellmeier equation.By calculating the corrected ultraviolet-visible light spectrum, the ultraviolet-visible light spectrums corresponding to the light path length of 1 to $25 \mathrm{~mm}$ are obtained,the color matching function can be used to calculate the tristimulus value XYZ29,30, and color space conversion can be used to obtain the color parameters $L^{*}, a^{*}$ and $b^{*}$ in the CIE $1976 L^{*} a^{*} b^{*}$ uniform color space ${ }^{35,36}$.The detailed conversion steps are detailed in the method. The synthetic ruby color parameters of the light path length from $1 \mathrm{~mm}$ to $10 \mathrm{~mm}$ are shown in Table 1 . 


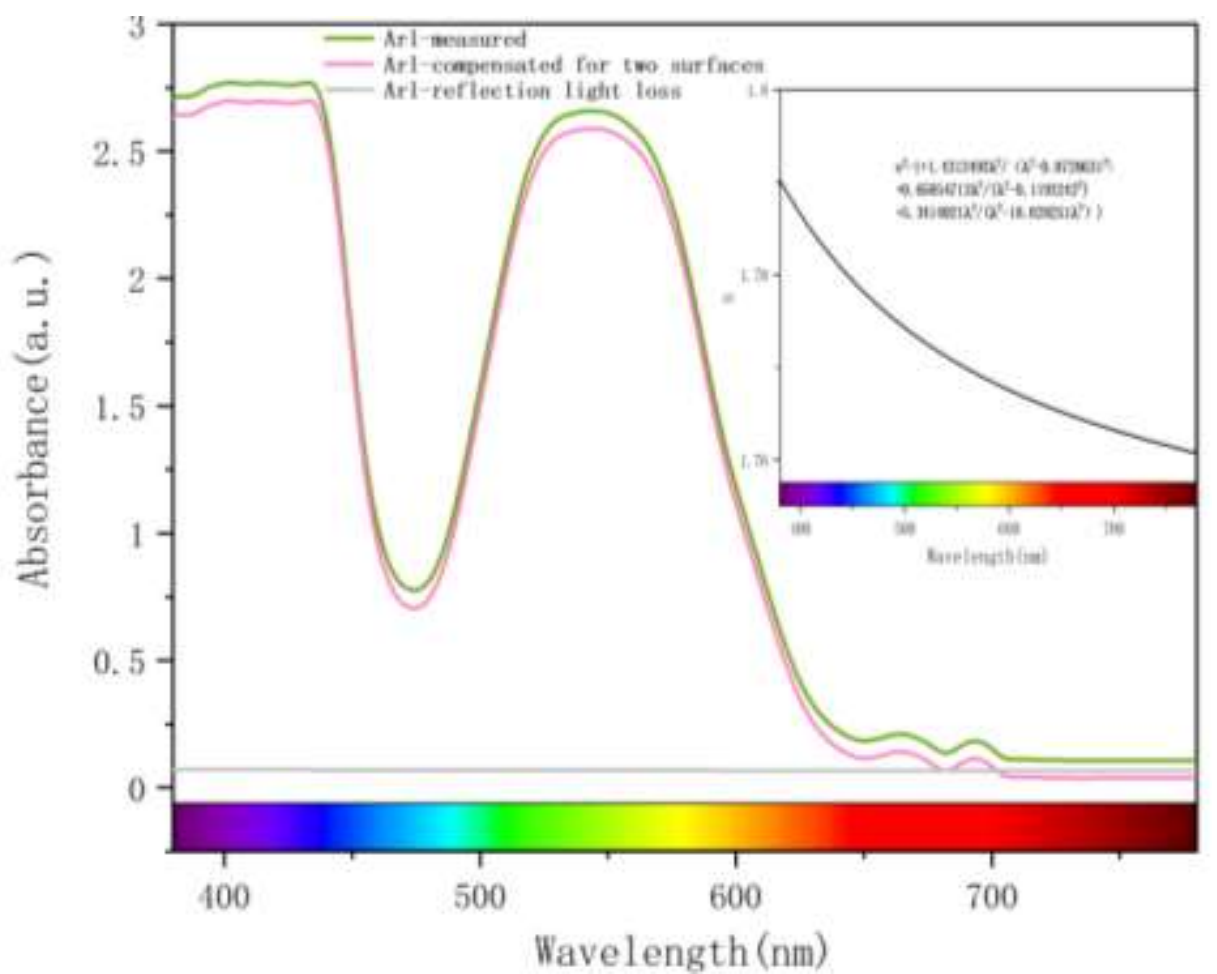

Figure 3. Corrected UV-Vis spectrum of the synthetic ruby $R_{\circ a}$.The green line is the original spectrum, the pink line is the corrected spectrum, and the gray line is Arl. The top right is the curve of the relationship between the corresponding refractive index and wavelength

\begin{tabular}{|c|c|c|c|c|c|c|c|}
\hline & Light path length & $\mathbf{R}_{\text {oa }}$ & $\mathbf{R}_{\text {ob }}$ & $\mathbf{R}_{\mathbf{e c}}$ & Ruoa & Ruob & $\mathbf{R u} \mathbf{e c}$ \\
\hline \multirow{6}{*}{$1 \mathrm{~mm}$} & $\mathrm{~L}^{*}$ for daylight D65 & 81.72 & 81.86 & 83.79 & 80.7 & 78.07 & 83.71 \\
\hline & $a^{*}$ for daylight D65 & 25.72 & 25.14 & 12.85 & 24.49 & 22.82 & 9.58 \\
\hline & $b^{*}$ for daylight D65 & -5.4 & -2.41 & -3.62 & -1.94 & -2.09 & 3.02 \\
\hline & $L^{*}$ for incandescent light $A$ & 85.02 & 85.12 & 85.65 & 84.16 & 81.29 & 85.51 \\
\hline & $a^{*}$ for incandescent light $A$ & 29.91 & 29.36 & 15.95 & 28.98 & 27.63 & 12.82 \\
\hline & $\begin{array}{l}b^{*} \text { for incandescent light } \\
\text { A }\end{array}$ & -3.3 & -3.06 & -2.37 & 0.65 & -2.58 & 1.51 \\
\hline \multirow{6}{*}{$2 \mathrm{~mm}$} & $\mathrm{~L}^{*}$ for daylight D65 & 69.35 & 69.5 & 71.19 & 67.51 & 63.43 & 70.68 \\
\hline & $a^{*}$ for daylight D65 & 43.56 & 42.81 & 24.26 & 41.95 & 39.78 & 18.37 \\
\hline & $b^{*}$ for daylight D65 & -7.82 & -5.2 & -5.81 & -1.43 & -3.94 & 3.2 \\
\hline & $L^{*}$ for incandescent light $A$ & 74.79 & 74.9 & 74.72 & 73.28 & 68.94 & 74.09 \\
\hline & $a^{*}$ for incandescent light $A$ & 48.75 & 48.1 & 29.57 & 47.64 & 46.24 & 24.08 \\
\hline & $\begin{array}{l}b^{*} \text { for incandescent light } \\
\text { A }\end{array}$ & -3.39 & -3.09 & -3.08 & 3.79 & -1.38 & 3.6 \\
\hline \multirow{6}{*}{$3 \mathrm{~mm}$} & $\mathrm{~L}^{*}$ for daylight D65 & 60.77 & 60.89 & 61.50 & 58.37 & 53.66 & 60.38 \\
\hline & $a^{*}$ for daylight D65 & 54.55 & 53.88 & 34.14 & 53.03 & 50.88 & 26.37 \\
\hline & $b^{*}$ for daylight D65 & -7.62 & -5.34 & -6.65 & 1.02 & -2.77 & 3.95 \\
\hline & $L^{*}$ for incandescent light $A$ & 67.55 & 67.64 & 66.46 & 65.56 & 60.65 & 65.16 \\
\hline & $a^{*}$ for incandescent light $A$ & 59.25 & 58.73 & 40.64 & 58.16 & 56.9 & 33.67 \\
\hline & $\begin{array}{l}b^{*} \text { for incandescent light } \\
\text { A }\end{array}$ & -1.09 & -0.79 & -2.28 & 8.53 & 2.54 & 6.25 \\
\hline $4 \mathrm{~mm}$ & $\mathrm{~L}^{*}$ for daylight D65 & 54.57 & 54.66 & 54.12 & 51.82 & 46.95 & 52.3 \\
\hline
\end{tabular}




\begin{tabular}{|c|c|c|c|c|c|c|c|}
\hline & $a^{*}$ for daylight D65 & 60.4 & 59.92 & 42.27 & 59.01 & 56.87 & 33.46 \\
\hline & $b^{*}$ for daylight D65 & -5.56 & -3.56 & -6.25 & 4.72 & 0.44 & 5.27 \\
\hline & $L^{*}$ for incandescent light $A$ & 62.16 & 62.23 & 60.23 & 59.83 & 54.79 & 58.22 \\
\hline & $a^{*}$ for incandescent light $A$ & 64.31 & 63.97 & 49.02 & 63.13 & 61.74 & 41.41 \\
\hline & $\begin{array}{l}b^{*} \text { for incandescent light } \\
\text { A }\end{array}$ & 2.64 & 2.89 & -0.2 & 13.97 & 7.88 & 9.42 \\
\hline \multirow{6}{*}{$5 \mathrm{~mm}$} & $\mathrm{~L}^{*}$ for daylight D65 & 49.87 & 49.93 & 48.49 & 46.91 & 42.12 & 46.00 \\
\hline & $a^{*}$ for daylight D65 & 62.93 & 62.63 & 48.52 & 61.50 & 59.18 & 39.42 \\
\hline & $b^{*}$ for daylight D65 & -2.44 & -0.66 & -4.78 & 8.94 & 4.69 & 7.12 \\
\hline & $L^{*}$ for incandescent light $A$ & 57.95 & 58.00 & 55.48 & 55.36 & 50.41 & 52.80 \\
\hline & $a^{*}$ for incandescent light $A$ & 66.21 & 66.01 & 54.82 & 64.80 & 63.05 & 47.25 \\
\hline & $b^{*}$ for incandescent light & 6.96 & 7.17 & 2.87 & 19.38 & 13.56 & 12.99 \\
\hline \multirow{6}{*}{$6 \mathrm{~mm}$} & $\mathrm{~L}^{*}$ for daylight D65 & 46.15 & 46.19 & 44.16 & 43.06 & 38.44 & 41.10 \\
\hline & $a^{*}$ for daylight D65 & 63.56 & 63.37 & 52.88 & 61.93 & 59.32 & 44.11 \\
\hline & $\mathrm{b}^{*}$ for daylight D65 & 1.12 & 2.74 & -2.47 & 13.16 & 9.15 & 9.41 \\
\hline & $L^{*}$ for incandescent light $A$ & 54.52 & 54.57 & 51.78 & 51.72 & 46.91 & 48.53 \\
\hline & $a^{*}$ for incandescent light $A$ & 66.45 & 66.34 & 58.40 & 64.70 & 62.55 & 51.25 \\
\hline & $\begin{array}{l}b^{*} \text { for incandescent light } \\
\text { A }\end{array}$ & 11.37 & 11.56 & 6.54 & 24.35 & 18.91 & 16.79 \\
\hline \multirow{6}{*}{$7 \mathrm{~mm}$} & $\mathrm{~L}^{*}$ for daylight $\mathrm{D} 65$ & 43.10 & 43.13 & 40.78 & 39.92 & 35.48 & 37.25 \\
\hline & $a^{*}$ for daylight D65 & 63.16 & 63.06 & 55.56 & 61.24 & 58.34 & 47.45 \\
\hline & $b^{*}$ for daylight D65 & 4.74 & 6.25 & 0.40 & 17.07 & 13.36 & 12.02 \\
\hline & $L^{*}$ for incandescent light $A$ & 51.64 & 51.67 & 48.82 & 48.64 & 43.99 & 45.09 \\
\hline & $a^{*}$ for incandescent light $A$ & 65.84 & 65.79 & 60.27 & 63.75 & 61.23 & 53.67 \\
\hline & $\begin{array}{l}b^{*} \text { for incandescent light } \\
\text { A }\end{array}$ & 15.59 & 15.76 & 10.50 & 28.72 & 23.62 & 20.63 \\
\hline \multirow{6}{*}{$8 \mathrm{~mm}$} & $\mathrm{~L}^{*}$ for daylight $\mathrm{D} 65$ & 40.52 & 40.54 & 38.07 & 37.27 & 33.00 & 34.18 \\
\hline & $a^{*}$ for daylight D65 & 62.27 & 62.21 & 56.91 & 60.03 & 56.88 & 49.54 \\
\hline & $b^{*}$ for daylight D65 & 8.23 & 9.64 & 3.58 & 20.55 & 17.10 & 14.80 \\
\hline & $L^{*}$ for incandescent light $A$ & 49.14 & 49.17 & 46.37 & 45.98 & 41.47 & 42.25 \\
\hline & $a^{*}$ for incandescent light $A$ & 64.83 & 64.81 & 60.94 & 62.42 & 59.59 & 54.84 \\
\hline & $\begin{array}{l}b^{*} \text { for incandescent light } \\
\text { A }\end{array}$ & 19.49 & 19.65 & 14.47 & 32.46 & 27.64 & 24.32 \\
\hline \multirow{6}{*}{$9 \mathrm{~mm}$} & $\mathrm{~L}^{*}$ for daylight $\mathrm{D} 65$ & 38.28 & 38.31 & 35.84 & 34.98 & 30.86 & 31.68 \\
\hline & $a^{*}$ for daylight D65 & 61.13 & 61.11 & 57.30 & 58.58 & 55.24 & 50.57 \\
\hline & $b^{*}$ for daylight D65 & 11.48 & 12.82 & 6.82 & 23.56 & 20.32 & 17.59 \\
\hline & $L^{*}$ for incandescent light $A$ & 46.94 & 46.97 & 44.29 & 43.62 & 39.22 & 39.86 \\
\hline & $a^{*}$ for incandescent light $A$ & 63.64 & 63.64 & 60.83 & 60.93 & 57.86 & 55.10 \\
\hline & $b^{*}$ for incandescent light $A$ & 23.03 & 23.17 & 18.25 & 35.60 & 30.99 & 27.74 \\
\hline \multirow{3}{*}{$10 \mathrm{~mm}$} & $\mathrm{~L}^{*}$ for daylight D65 & 36.32 & 36.35 & 33.95 & 32.96 & 28.96 & 29.59 \\
\hline & $a^{*}$ for daylight D65 & 59.90 & 59.89 & 57.04 & 57.06 & 53.57 & 50.80 \\
\hline & $b^{*}$ for daylight D65 & 14.46 & 15.74 & 9.98 & 26.12 & 23.03 & 20.24 \\
\hline
\end{tabular}




$\begin{array}{lllllll}\text { L }^{*} \text { for incandescent light A } & 44.96 & 44.99 & 42.47 & 41.50 & 37.19 & 37.78 \\ \text { a }^{*} \text { for incandescent light A } & 62.38 & 62.39 & 60.25 & 59.41 & 56.15 & 54.74 \\ \text { b }^{*} \text { for incandescent light } & 26.19 & 26.33 & 21.76 & 38.21 & 33.73 & 30.78 \\ \text { A } & & & & & & \end{array}$

Table 1. Synthetic ruby color parameters with light path length from $1 \mathrm{~mm}$ to $10 \mathrm{~mm}$

\section{Color calculation and colorimetric parameter maps analysis}

The color of transparent gems can be calculated based on the spectrum of the light source and the transmission spectrum of the gem.The integral of the spectral response curve corresponds to the signal emitted by the cone cells of the human eye.The reaction spectrum of the cone, the light source and the transmission spectrum of the sample are combined to determine the tristimulus value $X Y Z$ of the spectrum.The spectra of D65 light source and $A$ light source used in this paper and the corresponding $\bar{x}(\lambda), \bar{y}(\lambda), \bar{z}(\lambda)$ color matching function spectra are shown in Figure 4.The light source is represented by a colorimeter through a standardized spectrum.CIE D65 light source represents the average daylight with a correlated color temperature of about $6504 k$, and CIE A light source represents an incandescent lamp with a correlated color temperature of about 2856k(D65:X=95.04,Y=100,Z=108.87;A:X=109.85,Y=100,Z=35.58).

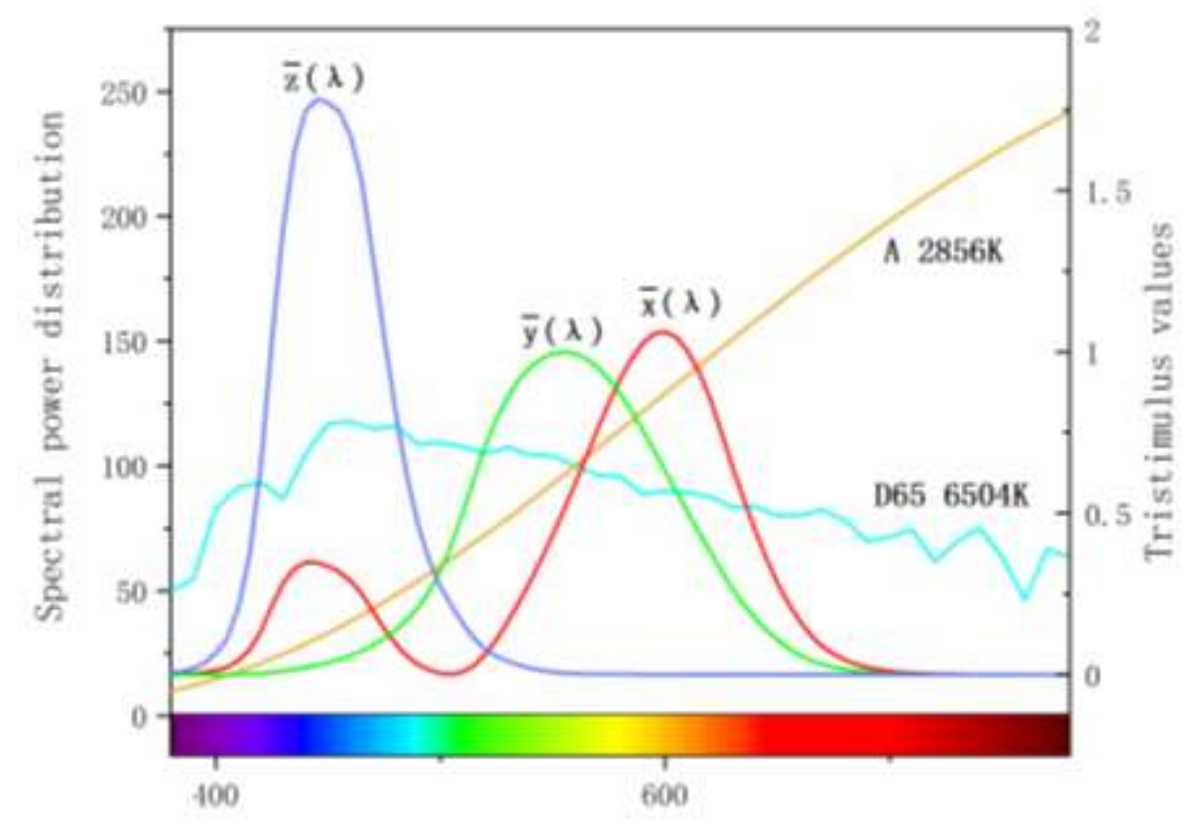

Figure 4.The spectral power distribution of the CIE D65 light source representing daylight (color temperature $6504 \mathrm{k}$ ), the spectral power distribution of the incandescent $\mathrm{CIE} A$ light source (color temperature 2856k) and the color matching function spectrum $\bar{x}(\lambda), \bar{y}(\lambda), \bar{z}(\lambda)$

The CIE XYZ color space is based on the uniform distribution of color perception, and colors will not be scattered in the Cartesian coordinate space,The calculated Euclidean distances between various color coordinates cannot be reasonably compared with each other.In the CIE $1976 \mathrm{~L}^{*} \mathrm{a}^{*} \mathrm{~b}^{*}$ color space, $\mathrm{a}^{*}$ and $\mathrm{b}^{*}$ represent horizontal and vertical Cartesian coordinate axes, $\mathrm{L}^{*}$ represents the displacement perpendicular to the circular $a^{*}-b^{*}$ grid.Different combinations of $a^{*}$ and $b^{*}$ can reproduce different tones, and the position of the color coordinate along $L^{*}$ indicates the brightness of the color.In the CIE 1976 L $^{*} \mathrm{a}^{*} \mathrm{~b}^{*}$ color space, the tristimulus value XYZ is non-linearly converted into color parameters. And calculate the chromaticity value $C^{*}$ and hue angle $h^{\circ}$ under D65 light source and $A$ light source.Taking sample $R$ as an example, the 
absorption spectrum of light passing through synthetic ruby along any crystal direction can be calculated by the following formula:

$$
\begin{gathered}
\mathrm{Am}=x \times \mathrm{R} \text { down } \mathrm{a}+y \times \mathrm{R} \text { down } \mathrm{b}+z \times \mathrm{R} \text { down } \mathrm{c} \\
x^{2}+y^{2}+z^{2}=r^{2}
\end{gathered}
$$

Where $A m$ is the absorption spectrum in either direction, $R$ down a is Roa's UV-Vis absorption spectrum, R down $b$ is Rob's UV-Vis absorption spectrum, R down $\mathrm{c}$ is Rec's UV-Vis absorption spectrum, $x, y, z$ are the Cartesian coordinates of the ray path length, and the ray path length is constrained to lie on a sphere with a radius of $r$.

(a)

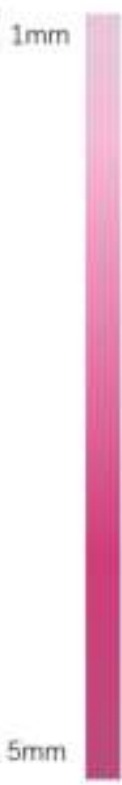

(b)
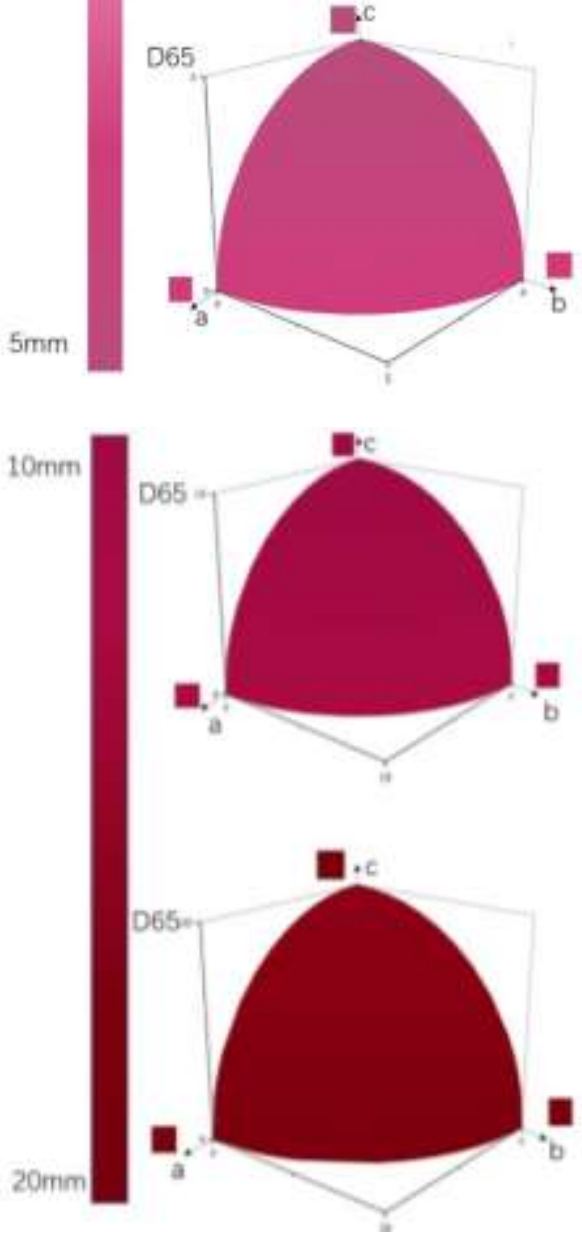
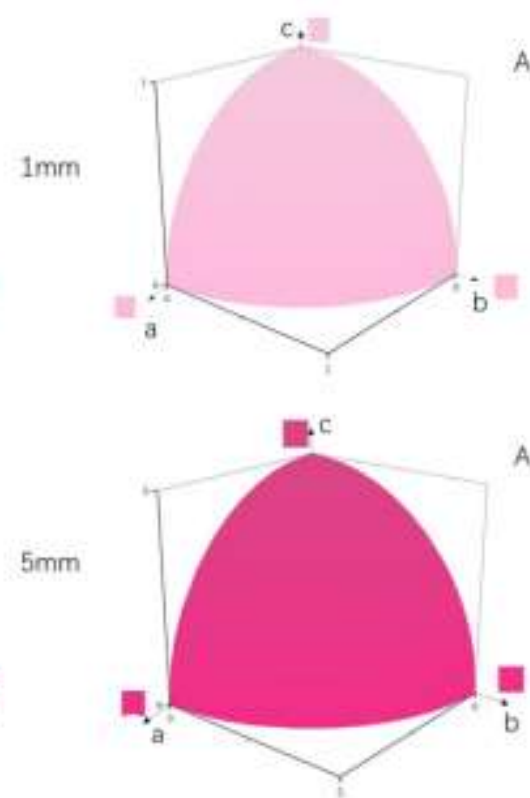

$5 \mathrm{~mm}$

$10 \mathrm{~mm}$
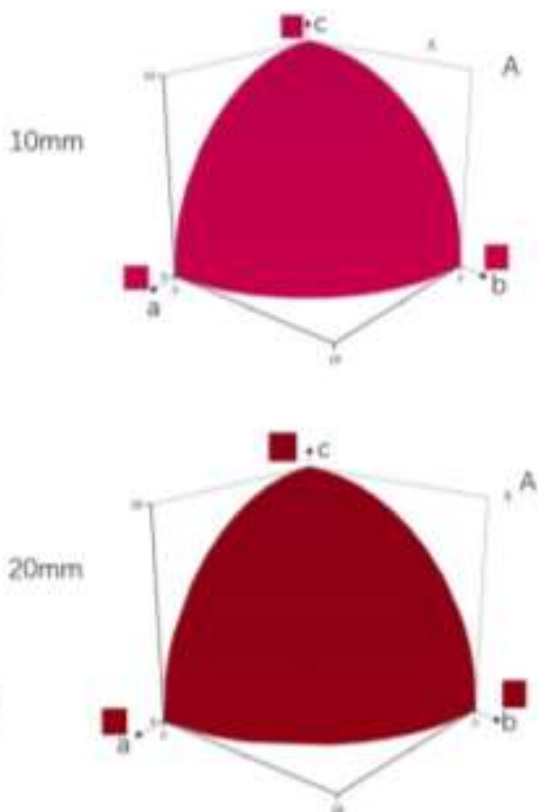
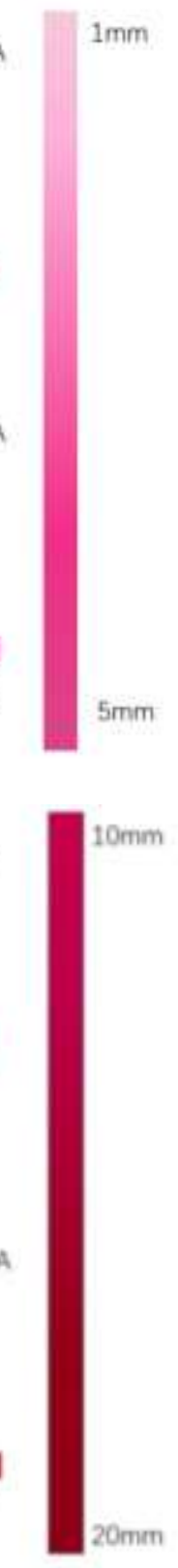

Figure 5. Synthetic ruby chromaticity diagram between $R_{o a}, R_{o b}$, and $R_{e c}$ of different light path lengths. The left column is the D65 light source, and the right column is the A light source. (a) $1 \mathrm{~mm}$ and $5 \mathrm{~mm}$ chromaticity diagram (b) $10 \mathrm{~mm}$ and $20 \mathrm{~mm}$ chromaticity diagram 
As shown in Figure 5, the color of the synthetic ruby under D65 and A light source increases with the increase of the light path length, from the original light pink to purple-red and finally to deep red.When the light path length is $1 \mathrm{~mm}$ and $20 \mathrm{~mm}$, the effect of different light sources on the color of ruby is not obvious.When the light path length is $5 \mathrm{~mm}$ and $10 \mathrm{~mm}$, the color difference between the two light sources can be observed from the figure.Therefore, only when the length of the light path is in the appropriate range, that is, the length of the light path is not too large or too small, the light source will have a significant effect on the color of the ruby.

When the light path length is $5 \mathrm{~mm}$, the color difference between a-axis (o-light direction) and c-axis (e-light direction) of synthetic ruby is the most obvious.In addition, when the light path length is $1 \mathrm{~mm}$, the color of the e-light direction is light pink. The color in the o-light direction is pink, and the color lightness in the e-light direction is greater than in the o-light direction.But when the light path length is increased to $5 \mathrm{~mm}$, the color in the e-light direction is already darker than the o-light direction. It shows that when the length of the illumination path is from $1 \mathrm{~mm}$ to $5 \mathrm{~mm}$, the change of the color lightness $\mathrm{L}^{*}$ in the e-light direction with the change of the illumination path length is greater than that in the o-light direction.This has to do with the pleochroism of ruby.It can be seen from Figure 5 that the length of the light path and the light source will affect the color of the synthetic ruby, and the colors of the synthetic ruby o-light and e-light directions are also different, so let's quantitatively discuss their influence on the color parameters of the synthetic ruby.

\section{The Influence of Light Path Length and Light Source on the Color of Synthetic Ruby}

Figures 6 to 8 show the sample color parameters $L^{*}, C^{*}, h\left(^{\circ}\right)$ for different light path lengths under $D 65$ and $A$ light sources.Take $R_{o a}, R_{o b}, R_{e c}, R u_{o a}, R u_{o b}$, and $R u_{e c}$ with different light path lengths as a set of samples.

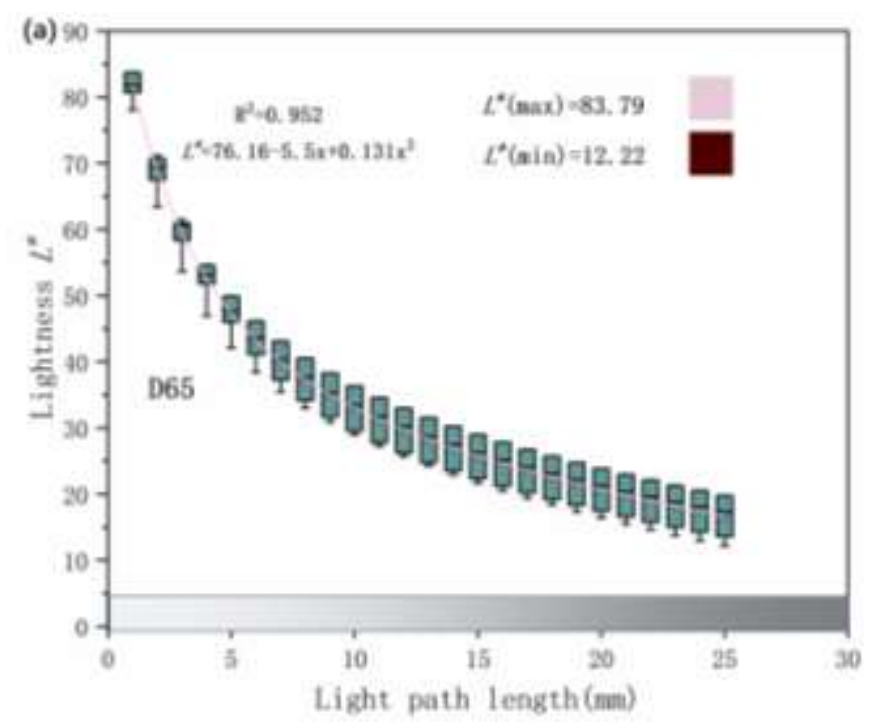




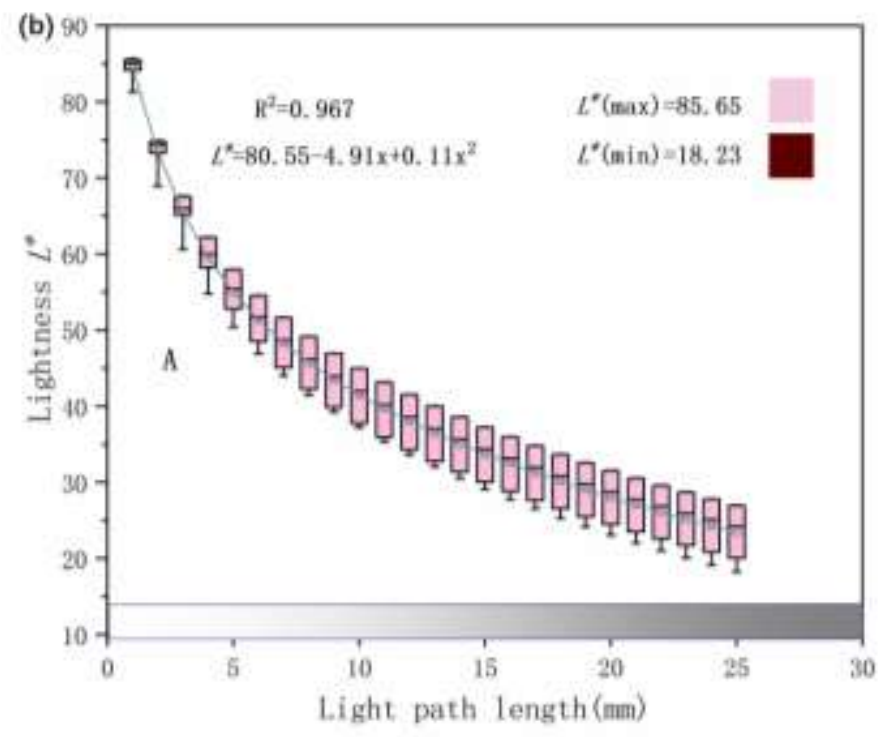

Figure 6 The Lightness $L^{*}$ of synthetic rubies with different light path lengths under two light (a) Synthetic ruby Lightness $L^{*}$ under D65 light source (b) Synthetic ruby Lightness $L^{*}$ under A light source

Figure 6 shows whether it is D65 light source or A light source, when the light path length increases, the lightness will decrease, showing a negative correlation $\left(R^{2}=0.952\right)$. This is consistent with the perception of the human eye.The lightness under the A light source is higher than the lightness under the D65 light source.When the length of the light path increases from $1 \mathrm{~mm}$ to $5 \mathrm{~mm}$, the lightness drops rapidly, indicating that when the length of the light path is very small, its change has a significant impact on the lightness.

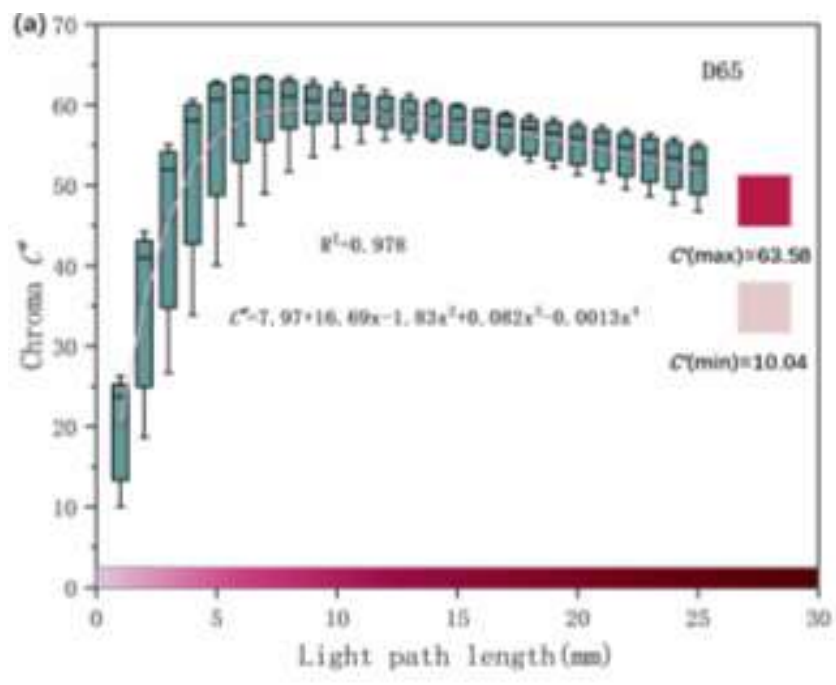




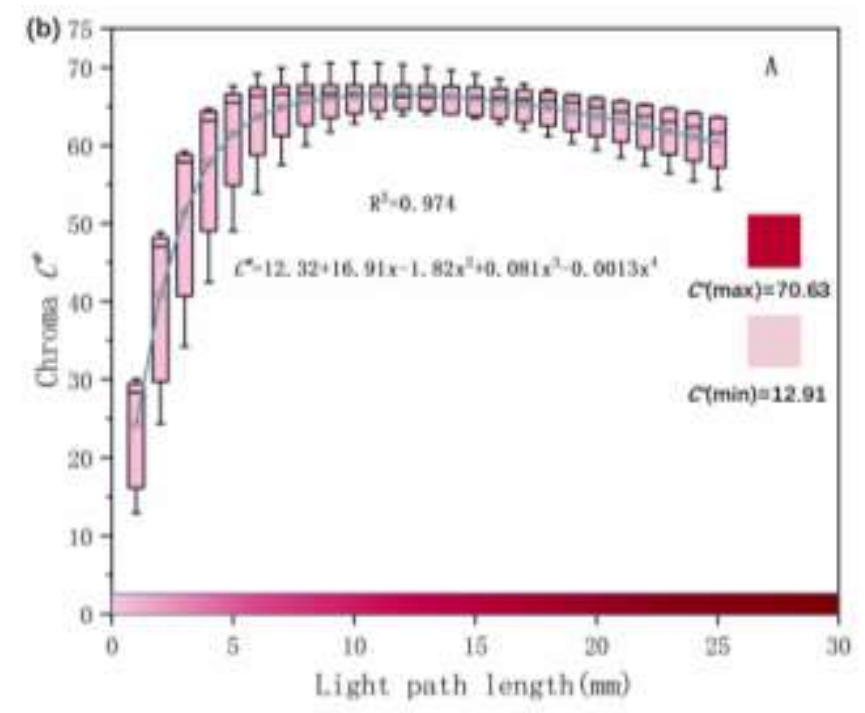

Figure 7 The chroma $C^{*}$ of synthetic rubies with different light path lengths under two light sources (a) Synthetic ruby chroma $C^{*}$ under D65 light source (b) Synthetic ruby chroma $C^{*}$ under A light source

Figure 7 shows that under D65 and A light sources, the chroma $C^{*}$ of synthetic rubies with different light path lengths increases first and then decreases. Under the D65 light source, when the light path length is less than $7 \mathrm{~mm}$, the chromaticity $C^{*}$ increases with the increase of the light path length, reaching the maximum value of 63.58; When the path length is greater than $7 \mathrm{~mm}$, the color saturation reaches saturation and begins to decrease. Under A light source, it is bounded by $10 \mathrm{~mm}$.

In addition, the chroma values of $\mathrm{Rec}_{\mathrm{ec}}$ and $\mathrm{Ru}_{\mathrm{ec}}$ under the two light sources are significantly lower than $\mathrm{R}_{\mathrm{oa}}$ and $\mathrm{Ru}_{\mathrm{oa}}$, which is caused by the pleochroism of the ruby.But under the D65 light source, when the light path length is $10 \mathrm{~mm}$ to $15 \mathrm{~mm}$, the chroma value is close.This is because $R_{o a}$ and $R_{u}$ oa reached the highest chroma and began to decline at $7 \mathrm{~mm}$, while $R_{e c}$ and $R u_{e c}$ continued to increase with the increase of the light path length because of the small chroma, and did not start to decrease until $12 \mathrm{~mm}$. The color temperature of $A$ light source is lower than that of D65 light source, so the chroma $C^{*}$ of $R_{o a}$ and $R u_{o a}$ starts to decrease at $10 \mathrm{~mm}$, while $R_{e c}$ and $R u_{e c}$ start to decrease at $14 \mathrm{~mm}$. 

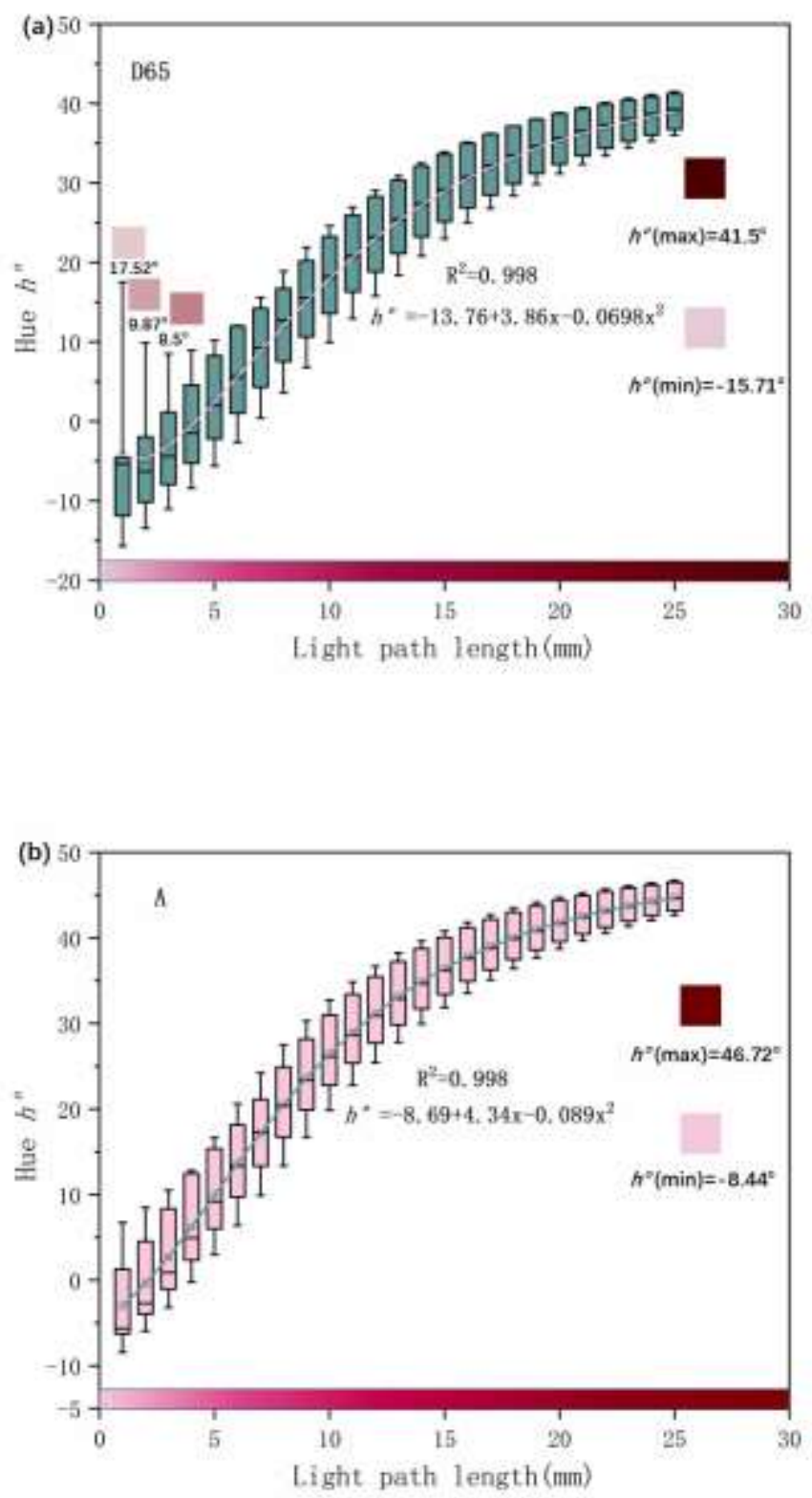

Figure 8 The hue angle of synthetic rubies with different path lengths under two light sources $h^{\circ}$

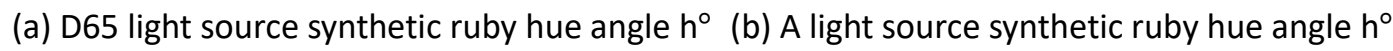

Figure 8 shows that the hue angle $h^{\circ}$ increases with the increase of the light path length under the two light sources, and the increasing amplitude gradually decreases.The hue angle under A light source is generally higher than that under D65 light source.But under the D65 light source, the hue angle $h^{\circ}$ decreases when Ruec (e light direction) is $1 \mathrm{~mm}$ to $3 \mathrm{~mm}$, and $h^{\circ}$ begins to increase after $3 \mathrm{~mm}$, this phenomenon does not appear under the $A$ light source.This is because when the length of the light path increases, the color changes from pink to light pink, and the chromaticity coordinate $a^{*}$ increases significantly, resulting in a decrease in hue angle $h^{\circ}$.The $A$ light source has a yellow hue, making the hue angle $h^{\circ}$ greater than that under the D65 light source, so the hue angle will not decrease due to the increase in the length of the light path.

The Influence of Light Path Length and Pleochroism on the Color Difference $\Delta \mathrm{E}^{*}{ }_{\mathrm{ab}}$ 
The color of synthetic ruby is plotted in CIE $1976 \mathrm{~L} * \mathrm{a} * \mathrm{~b} *$ color space.In the three-dimensional space, the line connecting the points under the two light sources represents the Euclidean distance, which is the color difference $\Delta \mathrm{E}^{*}$ ab.Project the three-dimensional $\mathrm{L}^{*} \mathrm{a}^{*} \mathrm{~b}^{*}$ color coordinates to the two-dimensional $a^{*} b^{*}$ plane (color circle), and draw a connecting line between the D65 light source and the A light source.In addition, link the change in the length of the light path with the color difference, draw a connecting line for each path length, and draw them in the same plane.The left end of the connecting line represents the color coordinate under the D65 light source, and the right end represents the color coordinate under the A light source.As shown in Figure 9, take $R_{\text {oa }}$ and $R_{\mathrm{ec}}$ as examples for drawing.

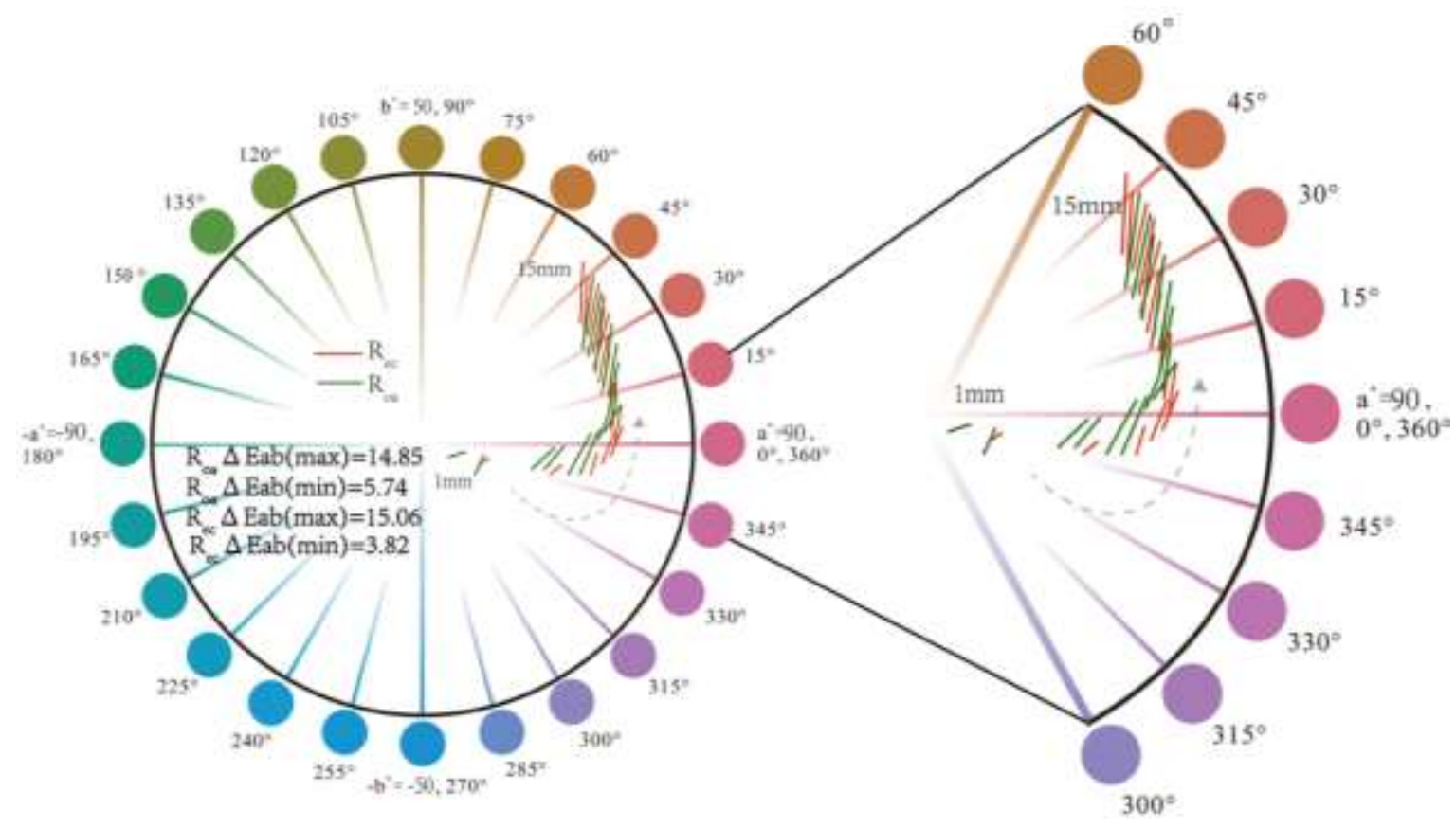

Figure $9 R_{\text {oa }}$ (o light direction) and $R_{\text {ec }}$ (e light direction) color difference $\Delta \mathrm{E}^{*}$ ab are distributed in two-dimensional $a^{*} b^{*}$ plane, the left end of the connecting line is the color coordinate of D65 light source, and the right end is the color coordinate of light source $A$

$R_{o a}$ and $R_{e c}$ are the o-light direction and e-light direction of synthetic ruby respectively.It can be seen from Figure 9 that as the length of the light path increases, the connecting lines are distributed in an upward trend in the two-dimensional a*b* plane.The color difference $\Delta \mathrm{E}^{*}$ ab in $R_{\text {oa }}$ and $R_{\text {ec }}$ both increases first and then decreases. When the light path length is $12 \mathrm{~mm}$, the color difference $\Delta \mathrm{E}^{*}$ ab reach the maximum, which are 14.85 and 15.06 respectively.In order to further explore the influence of the light path length on the color when the light source changes, the light path length is increased to $25 \mathrm{~m}$. 

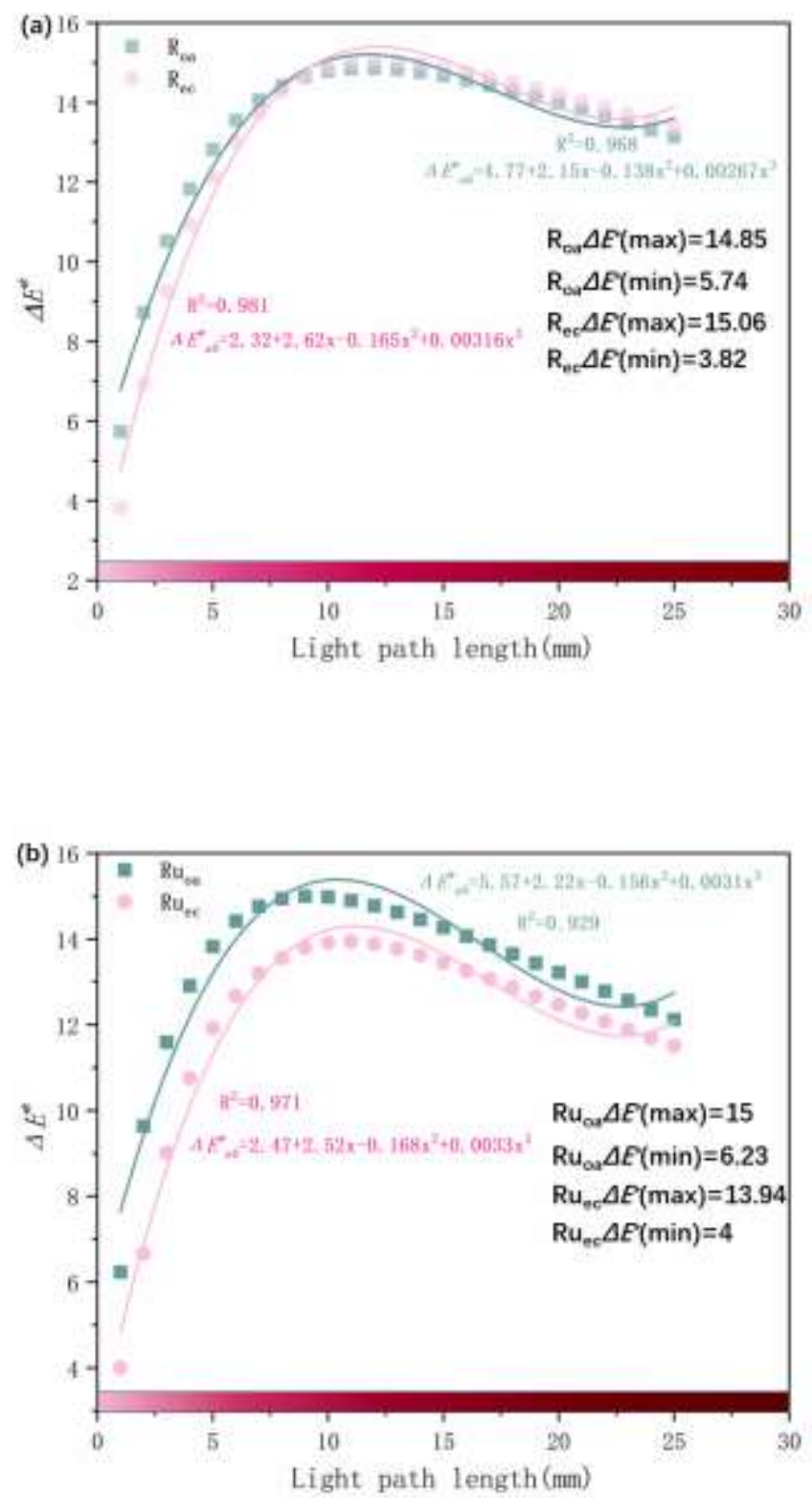

Figure 10 The color difference of different light path lengths in the o-light direction and e-light direction $\Delta \mathrm{E}^{*}{ }_{\mathrm{ab}}$ (a) $\mathrm{R}_{\mathrm{oa}}$ and $\mathrm{R}_{\mathrm{ec}}$ different light path length color difference $\Delta \mathrm{E}^{*}{ }_{\mathrm{ab}}$ (b) $\mathrm{Ru}_{\mathrm{oa}}$ and $\mathrm{Ru}_{\mathrm{ec}}$ different light path length color difference $\Delta E^{*}{ }^{*}$ b

As shown in Figure 10, increasing the light path length to $25 \mathrm{~mm}$, the color difference $\Delta \mathrm{E}^{*}$ ab continues to decrease, indicating that as the light path length increases, the influence of the light source on the color is weakened.By comparing Figure 10(a) and Figure 10(b), it is found that the color difference $\Delta \mathrm{E}^{*}$ ab changes of the two samples in the o-light and e-light directions are different, which is related to the color and pleochroism of the samples.

Effect of UV-Vis Absorbance Peak Area on the Color of Synthetic Ruby 


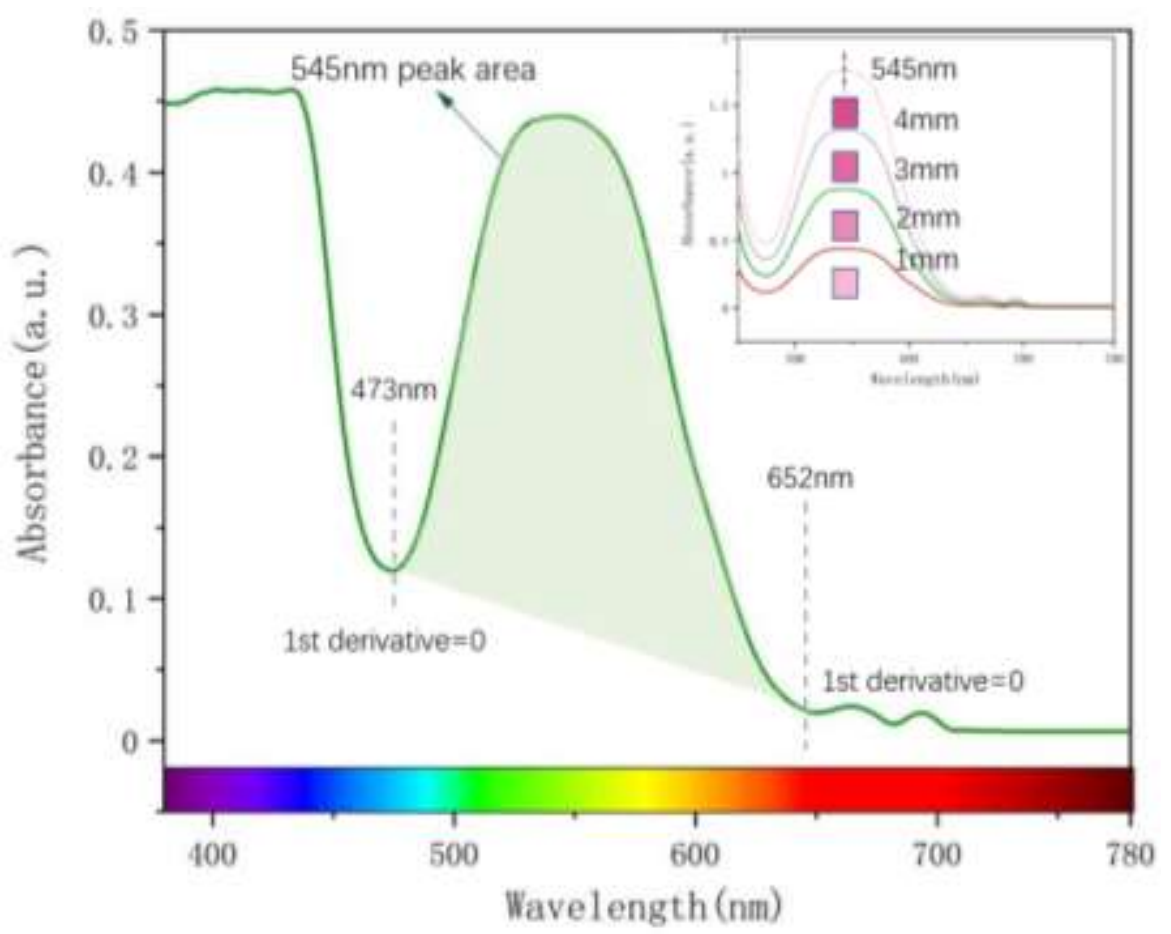

Figure 11 The absorption peak area $(X)$ at $545 \mathrm{~nm}$.Taking the sample $\mathrm{R}_{\text {oa }}$ as an example, the point where the first derivative is equal to zero is selected as the starting point and the end point of the $545 \mathrm{~nm}$ absorption peak range, and the absorption peak area is obtained by integrating from $473 \mathrm{~nm}$ to $652 \mathrm{~nm}$.The top right is the ultraviolet-visible light absorption spectra of different light path lengths

The strong absorption band at $545 \mathrm{~nm}$ in the ultraviolet-visible spectrum is caused by $\mathrm{Cr}^{3+}$, which absorbs yellow-green light in visible light and transmits red light, which has an important influence on the color of ruby.By calculating the first derivative of the ultraviolet-visible spectrum, the points with zero derivative near $473 \mathrm{~nm}$ and $652 \mathrm{~nm}$ are determined as the starting and ending points, and the absorption peak area at $545 \mathrm{~nm}$ is calculated(Figure 11).

Select a part of the data of different $545 \mathrm{~nm}$ absorption peak areas under D65 light source to plot 12.At the same time, it can be seen from Figure 11 that the $545 \mathrm{~nm}$ absorption peak area is positively correlated with the light path length. Figure 12 shows that the hue angle $h^{\circ}$ is positively correlated with the peak area at $545 \mathrm{~nm}$. When the absorption peak area increases, the hue angle $h^{\circ}$ increases.The $R^{2}$ of the hue angle under the D65 light source is $0.996 . h^{\circ}$ changed from -11.86 (that is, 348.14 ) to 36.75 .The lightness $L^{*}$ is negatively correlated with the peak area at $545 \mathrm{~nm}$. As the peak area increases, the ruby absorbs more visible light, and the lightness decreases.The chroma $\mathrm{C}^{*}$ first increases and then decreases with the absorption peak area, which is related to the changes of $L^{*}$ and $h^{\circ}$.When $h^{\circ}$ increases, $L^{*}$ decreases. When the length of the light path increases to a certain length, the decrease in brightness $L^{*}$ has a significant impact on chroma $\mathrm{C}^{*}$, making chroma $\mathrm{C}^{*}$ begin to decrease. 


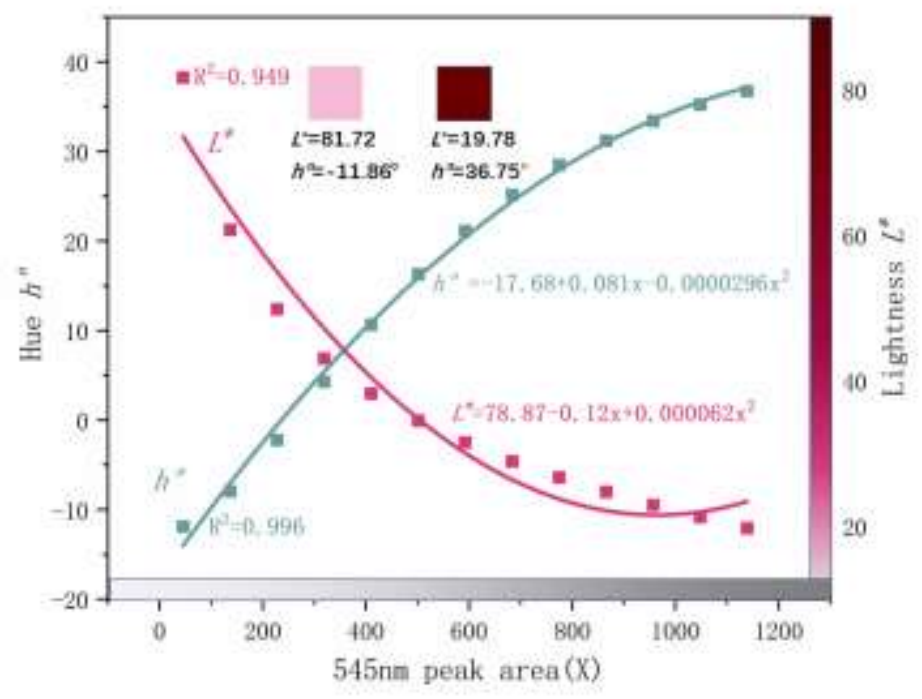

Figure $12 \mathrm{~L}^{*}$ and $\mathrm{h}^{\circ}$ of synthetic ruby with different UV-visible spectral peak areas under D65 light source

\section{Conclusion}

In the ultraviolet-visible spectrum of synthetic ruby, $\mathrm{Cr}^{3+}$ causes a strong absorption broadband at $545 \mathrm{~nm}$, which is the main cause of ruby color. The color parameters of synthetic rubies under different light sources are obtained through the ultraviolet-visible spectrum. The $L^{*}$, $C^{*}$, and $h^{\circ}$ of light source $A$ are higher than those of light source D65, so the color appearance of synthetic rubies under light source $A$ is more vivid.

When the light source is unchanged, the absorption peak area at $545 \mathrm{~nm}$ increases with the increase of the light path length, the absorption of visible light increases, and the lightness $L^{*}$ decreases.When the light path length is $1 \mathrm{~mm}$ to $5 \mathrm{~mm}$, its subtle changes will cause a significant decrease in lightness; The hue angle $h^{\circ}$ increases with the increase of the light path length, but under the D65 light source, when the light path length is 1 to $3 \mathrm{~mm}$, the $\mathrm{Ru}_{\mathrm{ec}}$ color shifts red, causing the hue angle $h^{\circ}$ to decrease;As the length of the light path increases, the chroma $C^{*}$ increases, but when the length of the light path increases to a certain length, the decrease of the lightness $L^{*}$ causes the chroma to start to decrease. At the same time, because ruby has pleochroism, the chromaticity value $C^{*}$ of $R_{o a}$ and $R_{u}$ is lower than that of $R_{e c}$ and $R u_{e c}$. As the length of the light path increases, the chroma $C^{*}$ increases, but when the length of the light path increases to a certain length, the decrease of the lightness $L^{*}$ causes the chroma to start to decrease. At the same time, because ruby has pleochroism, the chromaticity value $C^{*}$ of $R_{\text {oa }}$ and $R u_{o a}$ is lower than that of $R_{e c}$ and $R u_{e c}$. The color difference $\Delta E^{*}{ }^{*}{ }^{6} 5-\mathrm{A}$ first increases and then decreases with the increase of the light path length. When the length of the light path reaches about $10 \mathrm{~mm}$, the color difference reaches its maximum value. At this time, the light source has the greatest influence on the color. When the length of the light path continues to increase, the influence of the light source on the color is weakened.

From the above conclusions, we can know that the UV-Vis spectrum can be used to calculate the color of synthetic rubies with different light path lengths. Therefore, we believe that this 
method can be widely used in other gems and transparent minerals, providing great help for quantitatively describing their colors.

\section{Methods}

UV-Vis Spectroscopy. The UV-3600 UV-VIS spectrophotometer(Shimadzu,Tokyo,Japan) was used to carrry out the UV-Vis spectra.The test conditions were described as follows:the range of wavelength, $200-900 \mathrm{~nm}$; slit width $2 \mathrm{~nm}$;scanning speed medium;sampling interval $0.5 \mathrm{~s}$;scanning mode,single.

CIE1931 XYZ Colour Matching Functions. The International Commission on Illumination proposed the CIEXYZ color system in 1931, and the tristimulus value XYZ can be obtained by matching the isoenergetic spectrum.The tristimulus value can calculate the color based on the spectrum collected from the surface of the object or the transmission through the object:

$$
\begin{aligned}
& \mathrm{X}=\int_{\lambda} \mathrm{k} \varphi(\lambda) \overline{\mathrm{x}}(\lambda) d \lambda \approx \sum_{380}^{780} k \varphi(\lambda) \bar{x}(\lambda) \triangle \lambda \\
& \mathrm{Y}=\int_{\lambda} \mathrm{k} \varphi(\lambda) \overline{\mathrm{y}}(\lambda) d \lambda \approx \sum_{380}^{780} k \varphi(\lambda) \bar{y}(\lambda) \Delta \lambda \\
& \mathrm{Z}=\int_{\lambda} \mathrm{k} \varphi(\lambda) \overline{\mathrm{z}}(\lambda) d \lambda \approx \sum_{380}^{780} k \varphi(\lambda) \bar{z}(\lambda) \Delta \lambda \\
& \mathrm{k}=\frac{100}{\int_{\lambda} \mathrm{S}(\lambda) \overline{\mathrm{y}}(\lambda) \triangle \lambda}
\end{aligned}
$$

$S(\lambda)$ is the relative spectral power distribution of the observation light source.For non-luminous objects, $\varphi(\lambda)$ is the product of the spectral transmittance $T(\lambda)$ and the relative spectral power of the light sources $(\lambda)$, expressed as $\mathrm{T}(\lambda) \mathrm{S}(\lambda)$, or the product of the spectral reflectance $R(\lambda)$ and the relative spectral power distribution of the light sources $(\lambda)$, expressed $\operatorname{asR}(\lambda) S(\lambda) \cdot k$ is the naturalization coefficient. For non-luminous objects, the $Y$ value of the selected standard illuminant was adjusted to $100[31][32]$.

\section{Colour Space Conversion}

In order to describe easily colors, the color tristimulus values in CIEXYZ are non-linearly converted to obtain the color parameters $L^{*}, a^{*}, b^{*}$ in the CIE1976L*a*b* color space system.The formula for conversion is as follows:

$$
\begin{array}{r}
L^{*}=116\left(\frac{X}{X_{n}}\right)^{\frac{1}{3}}-16 \\
a^{*}=500\left[\left(\frac{X}{X_{n}}\right)^{\frac{1}{3}}-\left(\frac{Y}{Y_{n}}\right)^{\frac{1}{3}}\right] \\
b^{*}=200\left[\left(\frac{Y}{Y_{n}}\right)^{\frac{1}{3}}-\left(\frac{Z}{Z_{n}}\right)^{\frac{1}{3}}\right]
\end{array}
$$

For D65 light source, $X n=95.04, Y n=100, Z n=108.88$. For light source $A, X n=109.85, Y n=100$, and $\mathrm{Zn}=35.58 . \mathrm{Xn}, \mathrm{Yn}, \mathrm{Zn}$ are the colorimetric data obtained from the CIE1931 standard colorimetric observer $\left(2^{\circ}\right)$.

CIE1976 L*a*b* Colour System. The CIE1976L ${ }^{*} a^{*} b^{*}$ color space is the most widely used in the field of colorimetry.The system consists of plane chromaticity axes $a^{*}$ and $b^{*}$ and vertical axis $L^{*} . a^{*}$ stands for red, $-a^{*}$ stands for green; $b^{*}$ stands for yellow, $-b^{*}$ stands for blue.The chroma $C^{*}$ and hue angle $h^{\circ}$ can be calculated based on chromaticities $a^{*}$ and $b^{*}$.

$$
\begin{gathered}
C^{*}=\sqrt{a^{* 2}+b^{* 2}} \\
\mathrm{~h}=\arctan \frac{\mathrm{b}^{*}}{\mathrm{a}^{*}}
\end{gathered}
$$

To calculate the colour difference of rubies under different sources of illumination, we chose the 
$\operatorname{CIE} \operatorname{Lab}\left(\Delta \mathrm{E}^{*}{ }_{\mathrm{ab}}\right)$ color difference formula:

$$
\Delta \mathrm{E}_{\mathrm{ab}}^{*}=\sqrt{\left(\Delta L^{*}\right)^{2}+\left(\Delta a^{*}\right)^{2}+\left(\Delta b^{*}\right)^{2}}
$$

Where $\Delta \mathrm{a}^{*}=\mathrm{a}_{\mathrm{D} 65}^{*}-\mathrm{a}_{\mathrm{A}}^{*}, \Delta \mathrm{b}=\mathrm{b}_{\mathrm{D} 65}^{*}-\mathrm{b}_{\mathrm{A}}^{*}$, and $\Delta \mathrm{L}=\mathrm{L}_{\mathrm{D} 65}^{*}-\mathrm{L}_{\mathrm{A}}^{*}$, and $\Delta \mathrm{h}^{\circ}$ is the hue angle difference under different sources of illumination:

$$
\Delta \mathrm{h}=\mathrm{h}_{\mathrm{D} 65}-\mathrm{h}_{\mathrm{A}}
$$

Where $\Delta \mathrm{C}^{*}$ is the chroma difference under different sources of illumination:

$$
\Delta \mathrm{C}^{*}=\mathrm{C}_{\mathrm{D} 65}^{*}-\mathrm{C}_{\mathrm{A}}^{*}
$$

\section{Data availability}

The dataset for this study is available from the corresponding author upon reasonable request.

\section{References}

1. Dodd, D. M., Wood, D. L. \& Barns, R. L. Spectrophotometric Determination of Chromium Concentration in Ruby. J. Appl Phys. 35, 1183-1186 (1964).

2. Vassernis, R. I., Ostrovskaya, E. M., Perli, B. S., Sazonova, S. A. \& Skorobogatov, B. S. New method for measuring the average chromium concentration in ruby crystals. J. Appl. Spectrosc. 26, 39-41(1977).

3. King, J. M., Moses, T. M. \& Wang, W. Y. The impact of internal whitish and reflective graining on the clarity grading of D-to-Z color diamonds at the GIA laboratory. Gems Gemol. 42, 206-220 (2006).

4. King, J. M., Geurts, R. H., Gilbertson, A.M. \& Shigley, J. E. Color Grading "D-to-Z" Diamonds at the Gia Laboratory. Gems Gemol. 44, 296-321 (2008).

5. King, J. M., Moses, T. M., Shigley, J. E. \& Liu, Y. Color Grading of Colored Diamonds in the GIA Gem Trade Laboratory. Gems Gemol. 30, 220-242 (1994).

6. Stockton, C. M., Manson, D. V. Peridot from Tanzania. Gems Gemol. 19, 103-107 (1983).

7. Liu, Y., Shigley, J., Fritsch, E. \& Hemphill, S. The Alexandrite Effect in Gemstones. Color Res. Appl. 16, 186-191 (1994).

8. Sun, Z. Y. et al. Discovery of color-change chrome grossular garnets from Ethiopia. Gems Gemol. 54, 233-236 (2018).

9. Liu, Y., Shi, G. H. \& Wang, S. Color Phenomena of Blue Amber. Gems Gemol. 50, 134-140 (2014).

10. Sun, Z., Renfro, N. \& Palke, A. C. Tri-color-change holmium-doped synthetic CZ. Gems Gemol. 53, 259-260 (2017).

11. Guo, Y. Quality evaluation of tourmaline red based on uniform color space. Cluster Comput. 20, 3393-3408 (2017).

12. Guo, Y., Zhang, X. Y., Li, X. \& Zhang, Y. Quantitative characterization appreciation of golden citrine golden by the irradiation of $\left[\mathrm{FeO}_{4}\right]^{4-}$. Arab. J. Chem. 11, 918-923 (2018).

13. Tang, J., Guo, Y. \& Xu, C. Color effect of light sources on peridot based on CIE1976 L*a*b* color system and round RGB diagram system. Color Res. Appl. 44, 932-940 (2019).

14. Tang, J., Guo, Y. \& Xu, C. Metameric effects on peridot by changing background color. J. Opt. Soc. Am. A-Opt. Image Sci. Vis. 36, 2030-2039 (2019).

15. Tang, J., Guo, Y. and Xu, C. Light Pollution Effects of Illuminance on Yellowish Green Forsterite Color under CIE Standard Light Source D65. Ekoloji. 27, 1181-1190 (2018).

16. Cheng, R. P. \& Guo, Y. Study on the effect of heat treatment on amethyst color and the cause 
of coloration. Sci. Rep. 10, 1-12 (2020).

17. Wang, X. D. \& Guo, Y., The impact of trace metal cations and absorbed water on colour transition of turquoise. R. Soc. Open Sci. 8, (2021).

18. Guo, Y. Quality grading system of Jadeite-Jade green based on three colorimetric parameters under CIE standard light sources D-65, CWF and A. Bulg. Chem. Commun. 4, 961-968 (2017).

19. Jiang, Y. S. \& Guo, Y. Genesis and influencing factors of the colour of chrysoprase. Sci. Rep. 11, (2021).

20. Jiang, Y. S., Guo, Y., Zhou, Y. F., Li, X. \& Liu, S. M. The Effects of Munsell Neutral Grey Backgrounds on the Colour of Chrysoprase and the Application of AP Clustering to Chrysoprase Colour Grading. Minerals. 10, (2021).

21. Guo, Y., Zong, X. \& Qi, M. Feasibility study on quality evaluation of Jadeite-jade color green based on GemDialogue color chip. Multimed. Tools Appl. 1, 841-856 (2019).

22. Zhang, S. F. \& Guo, Y. Measurement of Gem Colour Using a Computer Vision System: A Case Study with Jadeite-Jade. Minerals. 11, (2021).

23. Tooms, M. S. Exploiting colorimetric relationships in characterizing the spectral response functions of the human visual system directly from colour matching functions. Color Res. Appl. 5, 782-795 (2020).

24. Kasajima, I. \& Sasaki, K. Dichromatism causes color variations in leaves and spices. Color Res. Appl. 6, 605-611 (2015).

25. Kasajima, I. Alexandrite-like effect in purple flowers analyzed with newly devised round RGB diagram. Sci. Rep. 6, (2016).

26. Sun, Z. Y., Palke, A. C. \& Renfro, N. Vanadium and Chromium-Bearing Pink Pyrope Garnet: Characterization and Quantitative Colorimetric Analysis. Gems Gemol. 4, 348-369 (2015).

27. Qiu, Y. \& Guo, Y. Explaining Colour Change in Pyrope-Spessartine Garnets. Minerals. 8, (2021).

28. Sun, Z. Y., Palke, A. C., Muyal, J. \& McMurtry, R. How to facet gem-quality chrysoberyl: Clues from the relationship between color and pleochroism, with spectroscopic analysis and colorimetric parameters. Am. Miner. 8, 1747-1758 (2017).

29. Renfro, N. \& McClure, S. F. Dyed Purple Hydrophane Opal. Gems Gemol. 4,260-270 (2011).

30. Fairchild, M. D. Color appearance models and complex visual stimuli. J. Dent. E25-E33 (2010).

31. Hughes, R. W. Pleochroism in Faceted Gems: An Introduction. Gems Gemol. 3, 216-226 (2014).

32. Huang, R. R. \& Yin, Z. W. Spectroscopy Identification of Untreated and Heated Corundum. Spectrosc. Spectr. Anal. 1, 80-84 (2017).

33. Tippins, H. H. Charge-Transfer Spectra of Transition-Metal Ions in Corundum. Phys. Rev. B. 1, 126-135 (1970).

34. Malitson., I. H. \& Dodge., M. J. Refractive-index and birefringence of synthetic sapphire. J. Opt. Soc. Am. 11, 1405-1405 (1972).

35. Liao, N.F., Shi, J.S. \& Wu, W.M. An Introduction to Digital Color Management System. Beijing Institute of Technology Press. (2009).

36. Foster, David., Marín-Franch, Iván., Nascimento, Sérgio \& Amano, Kinjiro. Coding efficiency of CIE color spaces. 16th Color and Imaging Conference Final Program and Proceedings, pp. 4, 285-288 (2008).

\section{Acknowledgements}


The experiments in this research were completed in the Lab of Gemological Research at School of Gemmology, China University of Geosciences (Beijing).

\section{Author contributions}

B.Y. and Y.G. chose raw materials as samples and conducted experiments and data analysis together, B.Y. and Z.Y.L wrote the main manuscript texts and prepared figures, and Y.G. revised and corrected the manuscript texts.

\section{Competing interests}

The authors declare no competing interests. 